\title{
THE EFFECTS OF EMOTIONAL INTELLIGENCE ON STUDENTS' SPEAKING SKILLS
}

\author{
Meiva Eka Sri Sulistyawati \\ AMIK BSI Bekasi, meiva.mes@bsi.ac.id
}

\begin{abstract}
Emotional Intelligence and students' speaking skills are correlated. This research aims to examine the effects of Emotional Intelligence on students' speaking skills. The observed population of this research was the XII graders students of the State Senior High Schools in East Jakarta. The sample was taken using simple random sampling technique. The data were garnered from questionnaire, objective test, and oral test for both variables. The gained data were then analyzed by using correlation formula and multiple regressions. The empirical evidence showed that there was a significant effect of Emotional Intelligence on the students' speaking skills given the Sig value 0.000 and t observed $=4.375$. Since Sig value was less than 0.05 and $t$ observed was higher than $t$ table, it indicated that $\mathrm{H}_{0}$ was rejected, which means that $\mathrm{H}_{1}$ was accepted. It illustrated that there was a significant effect of independent variable $\mathrm{X}$ (emotional intelligence) on the dependent variable Y (student's speaking skills).
\end{abstract}

Keywords: Emotional intelligence, speaking skills, teaching

\section{INTRODUCTION}

Language is the way to communicate, to express our feelings and to convey what on our minds to other people with symbols, sounds, gestures, and letters. With these elements, other people are able to understand our words with their meanings. According to the Vygostsky (1978-1986), language is a tool aid to achive a goal and to finish different kind of problems in a real life. Language is seen as an effective tool to create a competitive and a stong student. The English language is becoming increasingly important in a world in which political, social, and trading barriers between people are rapidly diminishing. 
English in Indonesia is taught from the early level that is elementary or even primary school until the highest level of educational system. Moreover, learning English means learning language components and language skills. There are some examples of language components such as grammar, vocabulary, pronunciation, and spelling. Meanwhile, as we know that there are for language skills that should be taught to the students. The skills are reading, listening, speaking, and writing. Among the four skills, speaking is often considered as the most difficult skill to be learned by the students. There is a very slow improvement maybe seen at school on those four aspects at students' ability. But, the worst is speaking. Many Indonesian learners are very bad at speaking. They might understand what they read, what they heard, and sometimes they know what to write; but it's rarely happen for them to reply those questions orally. Most students can answer well the questions that have been given literally but they become speechless when they have to answer them orally. Here, teachers have come to the dead end.

Speaking skill is one of the very important skills that every student must gain. By mastering the speaking skill, students will be able to express their feeling and opinion appropriately related to the context and the situation. This speaking skill will also create a creative generation in the future that can bear a good, a perfect, and a communicative utterance that easily to be understood. On the other side, this speaking skill will also create a generation with a good character and it will appear in a public conversation. Everyone will use good and wise words in communicating each other. The choice of good and proper words will bear a warm situation and it will make people more civilized. Speaking skill is one of the parts of the language skills which is developed in teaching English lesson according to the curriculum of Senior High School in Indonesia. The aim itself stated that we have to educate our spoken and writing skills; so that the students will be able to use the language as a communication tool and to absurd knowledge and information from other sources.

Bygate (1987:26) said that in spoken language a man must have a motoric perspective and interactive skills. Someone's 
thinking ability in expressing his/her ideas will usually appear when he or she does the talking, but this does not always happen to all students. In fact, most of them have many problems with speaking. Sometimes, a new learner will make a lot of mistakes in delivering the messages that he/she wants to say; even the messages are hard to understand. This kind of problem makes the students unconfident to speak. They feel shy of making mistakes when people are laughing at them. On the other hand, the environmental factors also give a contribution on their problem. Most of the problem is related with their emotional factors which are given the biggest contribution on those barriers.

Many teachers have admitted that learning to talk in the foreign language is often considered being one of the most difficult aspects of language learning for them to help their students with. Helping the students develop the speaking skill is not merely so that the students can pass the exam; but also, for more general use when they want to use English in the outside world after they are graduated from school. Mastering speaking skills needs a lot of practices and braveries to talk. Most students have lack of confidence when they try to talk in English. There are many factors which influences it. But the factors from inside are the strongest. Emotional intelligence has a great role on students' speaking skills.

Emotional intelligence is the ability to constructively study with all our emotions by identifying and communicating them (through appropriate expression and exploration); listening to what they are signaling to us about perceived or real threats to our wellbeing, so that we may examine these perceptions and becoming more aware of how they reflect our socio-cultural belief. It is very important to understand that emotional intelligence is not the opposite of intelligence. Emotional intelligence, then, is the ability to use your emotions to help you solve the problems and live in a more effective life. Both of them are the part of solution. Emotional intelligence has also the benefits in making good relationships.

Emotional intelligence can be used as a key factor in the success of learning. The instrumental factor in the success is the reflection of emotional intelligence. Emotional intelligence of a 
student with another student is different. It can be seen in daily life that some students succeeded and the others are failed.

Based on the description above, it can be concluded that speaking skill is very important for the students to communicate with others and to express what they feel about. There are some factors affecting speaking skill. The writer believes that Emotional Intelligence is relevant to explain about how far the factor gives some effects for the students' speaking skills.

\section{LITERATURE REVIEW}

\section{a. The Nature of Speaking}

Speaking is very important part in studying English. People need to speak in order to communicate each other and make a good communication. When someone was born, he learns how to communicate with his parents and people around him. Moreover, people grew up and try to convey their mind by using languages. That's the reason why every person has their own mother language. Mother language is formed by the environment and the culture.

Speaking is so much part of daily life that we take it for granted. The average person produces ten of thousands of words a day, although some people-like auctioners or politicians-may produce even more than that. So, the natural and integral is speaking that we forget how we once struggled to achieve this ability-until, we have to learn how to do it all over again in foreign language.

Speaking is a form of communication (Jone, 1989: 14). It means that speaking is a kind of communication which is conveyed orally. It is certainly that the process of it involves on two sides, there are the speaker and the listener who may function interchangeably. When the speaker produces utterances that sent to the listener, he/she may function as a speaker; and vice versa. In short, it may be said that speaking has the similar meaning with oral communication.

Brown said that conversations are collaborative activities as participants (speakers and listeners) engage in a process of negotiation of meaning. (Brown, 2001: 268). Moreover, Brown and 
Yule said that in the production of speech, each speaker needs to speak individually and ideally. He needs someone to listen to his speaking and respond to him. (Brown and Yule, 1997: 25). It may be inferred that speaking is a collaborative activity between a speaker and a listener/s in which the two parties want to convey and negotiate thoughts, feelings or messages in special reciprocal situation underlined by a mutual understanding. The main objective of the speaker is to be understood and to be interpreted properly by the listener/s. (Celce-Murcia and Olstain, 2000: 168)

From the nature of speaking above, it can be inferred that speaking is the means of communications comprising at least two persons, in face-to-face interaction, to produce ideas, thought, knowledge, and belief as well as they meet communicative language components to build the relationships in order to convey their messages.

b. Students' Speaking Skills

Speaking skill is one of the very important skills that every student must gain. By mastering the speaking skill, students will be able to express their feeling and opinion appropriately related to the context and the situation. This speaking skill will also create a creative generation in the future that can bear a good, a perfect, and a communicative utterance that easily to understood. On the other side, this speaking skill will also create a generation with a good character and it will appear in a public conversation. Everyone will use good and wise words in communicating each other. The choice of good and proper words will bear a warm situation ad it will make people more civilized. Speaking skill is one of the part of the language skills which is developed in teaching English lesson according to the curriculum of Senior High School in Indonesia. The aim itself stated that we have to educate our spoken and writing skills; so that the students will be able to use the language as a communication tool and to absurb knowledge and information from other sources.

Bygate (1987:26) said that in spoken language a man must have a motoric perspective and interactive skills. Someone's thingking ability in expressing his/her ideas will usually appear when he or she does the talking, but this is not always happen to all students. In fact, most of them have many problems with speaking. 
Sometimes, a new learner will make a lot of mistakes in delivering the messages that he/she wants to say; even the messages are hard to understand. This kind of problem makes the students unconfident to speak. They feel shy of making mistakes when people are laughing at them. On the other hand, the environmental factors also give a contribution on their problem. Most of the problem is related with their emotional factors which is given the biggest contribution on those barriers.

There are five basic types of speaking, there are:

a. Imitative. At one end of a continuum of types of speaking performance is the ability to simply parrot back (imitate) a word or phrase or possibly a sentence. While this is a purely phonetic level of oral production, a number of prosodic, lexical and grammatical properties of language may be included in the criterion performance.

b. Intensive. A second type of speaking frequently employed in assessment contexts in the production of short stretches of oral language design to demonstrate competence in a narrow band of grammatical, phrasal, lexical or phonological relationships (such as prosodic elements-intonation, stress, rhythm, juncture).

c. Responsive. Responsive assessment tasks include interaction and test comprehension but at the somewhat limited level of a very short of conversations, standard greetings and small talk, simple requests and comments, and the like. The stimulus is almost always a spoken prompt (in order to preserve authenticity), with perhaps only one or two followup questions or retorts.

d. Interactive. The difference between responsive and interactive speaking is the length and complexity of the interaction, which sometimes includes multiple exchanges or sometimes multiple participants. Interactions can take two forms of transactional languages, which has the purpose of exchanging specific information, or interpersonal exchanges, which have the purpose of maintaining social relationships.

e. Extensive (monologue). Extensive oral production tasks include speeches, oral presentations, and story-telling during 
the opportunity for oral interaction from listeners is either highly limited or ruled out together.

There are three main reasons for getting students to speak in the classroom. Firstly, speaking activities provide rehearsal opportunities-chances to practice real-life speaking in the safety of the classroom. Secondly, speaking tasks in which students try to use any or all of the languages they know provide feedback for both teacher and students. Everyone can see how well they are doing; both how successful they are, and also what language problems they are experiencing. And finally, the more students have opportunities to activate the various elements of languages they have stored on their brains, the more automatic their use of these elements become. As a result, students gradually become autonomous language users. This means that they will be able to use words and phrases fluently without very much conscious thought.

Good speaking activities can and should be extremely engaging for the students. If they are all participating fully-and if the teacher has set up the activity properly and can then give sympathetic and useful feedback-they will get tremendous satisfaction from it.

They are practicing what Scoot Thornbury, in his book How to Teach Speaking, calls speaking-as-skill, where there is a task to complete and speaking is the way to complete it. He suggests that the teaching of speaking depends on there being a classroom culture of speaking, and that classroom needs to become 'talking classrooms'. In other words, students will be much more confident speakers (and their speaking abilities will improve) if this kind of speaking activation is a regular feature of lesson.

\section{b. The Nature of Intelligence}

Intelligence comes from the Latin verb "intellegere" (Wikipedia), which means "to understand". By this rationale, intelligence (as understanding) is arguably different from being "smart" (able to adapt to one's environment), or being "clever" (able to creatively adapt). There are various definitions about intelligence, and there are so many controversies about the 
definition of intelligence. Every psychologist has difference opinion about nature of intelligence. (Woolfolk, 2008:168)

Below are the definitions about intelligence according to:

1. Charles Spearman

A psychologist from England, he found $G$ factors theory (General Intelligence) in related to the ability to solve the problem, abstract thinking and skills in learning. He concluded that all tasks and mental achievement only ask two kinds of quality i.e. general intelligence (general factors) and individual skills in certain field (specific factors). The intelligent people have more general factors.

2. L. L Thurnstone

He is more emphasizing in separated aspects of intelligence. According to Abdul Rahman Saleh's book (2004:252), Thursstone suggested that intelligence always a composite of special factors. He measured seven components with a famous test (The Primary Mental Test).

3. William Stern

Intelligence is mental ability to adapt rapidly in such changing situation by using thinking tools which appropriate with the objective. He argue that intelligence is mostly determined by heredity or genetic.

4. Raymond Cattel and John Horn

Found the Fluid Intelligence and Crystalized Intelligence. Those theories are further development from General Intelligence Theory.

5. Robert J. Sternberg

Sternberg (1997:1030) is proposed the definition of intelligence as composing the mental abilities necessary for adaptation to, as well as shaping and selection of, any environmental context. This definition can lead us to a broader conceptualization of the role of intelligence in lifelong learning. He found Triarchic Intelligence which is as a cognitive process approach to comprehending intelligence. He said that a successful person has equivalence in creativity, analytical and practical intelligence.

6. Howard Gardner

Gardner from Harvard University found the Multiple Intelligence Theory. He suggested that intelligence is biological and psychological potency to solving problem and creating outcome 
which is appreciated by the culture. Every human has more than one intelligence with the difference in development degree.

Nowadays, we speak of many different kinds of intelligence. In each case, intelligence refers to the capacity to perceive, understand, and use symbols: that is to reason abstractly. For example, if we talk of verbal intelligence, spatial intelligence, social intelligence, and other interrelated intelligences. The modifierverbal, spatial, or social-specifies the intelligences and what what it refers to. So, verbal intelligence denotes the capacoty to understand and use words. Spatial intelligence denotes the capacity to understand and use the objects in space. Social intelligence denotes the capacity to understand and use social information. Within psychology, EI belongs to the same group of interrelated intelligences and denotes the capacity to understand and use emotional information. In addition, EI plausibly reflects the emotion system's capacity to enance intelligence.

The American Psychologist, William James, stated that "We cry because we feel sorry, strike because we angry, tremble because we are afraid." (Morgan, et. Al., 1986: 330). Benjamin Bloom and his collegues provided an useful extended definition of the emotional side that is still widely used today: receiving, responding, valuing, organizing, and value the system" (Brown, 2000: 143). Another Psychologist, Goleman also argues, "all emotion are in essence, impulse to act, the instant plans for handling life that evolution has instilled us. The very root of the word emotion is motere the latin verb "to move" plus the prefix e- to connote "move away", suggesting that a tendency to act is implicit in every emotion." (Goleman, 1995: 6)

In our emotional repertoire, each emotion plays a unique role, as revealed bytheir distinctive biological signatures. With new methods to peer into the body and brain, researchers are discovering more psychological details of how emotion prepares the body for a very different kind of response.

Seeing kinds of emotions for in terms of their responses, it seems that anger, fear, happiness, love, surprise, disgust, and sadness all depend on our life experiences and cultures. Emotional intelligence gives us awareness of our own and other people's feelings. It gives empathy, sympathy, motivation, and the ability to 
respond appropriately to pain or pleasure. Emotional intelligence is a basic requirement for the effective use of intelligence quotient.

Based on the explanation above, it can be concluded that the intelligence is the mind that includes a number of capabilities, such as the ability to reason, plan, solve problems, think abstractly, understand ideas, using languages and learning; it is closely related to cognitive abilities possessed by individuals.

\section{c. The Nature of Emotional Intelligence}

The field of Emotional Quotient (EQ) or known as Emotional Intelligence (EI) began as a topic of study within academic psychology. From there, educators, psychiatrists, human resource specialists, and others became interested, and the field grew. Today, popular magazines and articles report on the field's activities, which rigorous scholarly journals publish articles in the area.

In 1983, Gardner published his research, that we known as multiple intelligences, by developing a theory of intelligence that includes four additional capabilities that were not previously on IQ. The first are focused on the musical and kinesthetic; while two others are focused on inter-personal and intra-personal intelligence. Interpersonal skill and thus form intra personal intelligence.

The model introduced by Daniel Goleman focuses on EI as a wide array of competencies and skills that drive leadership performance. Goleman's model outlines five main EI constructs (on "What Makes A Leader" by Daniel Goleman, best of Harvard Business Review 1998):

1. Self-awareness. The ability to recognize an emotion as it "happens" is the key to your EQ. Developing self-awareness requires tuning in to your true feelings. If you evaluate your emotions, you can manage them. The major elements of selfawareness are:

- Emotional awareness. Your ability to recognize your own emotions and their effects to the use of external tests as a device for affecting educational process.

- Self-confidence. Sureness about your self-worth and capabilities. 
2. Self-regulation. You often have little control over when you experience emotions. You can, however, have some say in how long an emotion will last by using a number of techniques to alleviate negative emotions such as anger, anxiety or even depression. A few of these techniques include recasting a situation in a more positive light, taking a long walk and meditation or prayer. Self-regulation involves

- Self-control. Managing disruptive impulses.

- Trustworthiness. Maintaining standards of honesty and integrity.

- Conscientiousness. Taking responsibility for your own performance.

- Adaptability. Handling change with flexibility.

- Innovation. Being open to new ideas.

3. Motivation. To motivate yourself for any achievement requires clear goals and a positive attitude. Although you may have a predisposition to either a positive or a negative attitude, you can with effort and practice learn to think more positively. If you catch negative thoughts as they occur, you can reframe them in more positive terms — which will help you achieve your goals. Motivation is made up of:

- Achievement drive. Your constant striving to improve or to meet a standard of excellence.

- Commitment. Aligning with the goals of the group or organization.

- Initiative. Readying yourself to act on opportunities.

- Optimism. Pursuing goals persistently despite obstacles and setbacks

4. Empathy. The ability to recognize how people feel is important to success in your life and career. The more skillful you are at discerning the feelings behind others' signals the better you can control the signals you send them. An empathetic person excels at:

- Service orientation. Anticipating, recognizing and meeting clients' needs.

- Developing others. Sensing what others need to progress and bolstering their abilities. 
- Leveraging diversity. Cultivating opportunities through diverse people.

- Political awareness. Reading a group's emotional currents and power relationships.

- Understanding others. Discerning the feelings behind the needs and wants of others.

5. Social skills. The development of good interpersonal skills is tantamount to success in your life and career. In today's alwaysconnected world, everyone has immediate access to technical knowledge. Thus, "people skills" are even more important now because you must possess a high EQ to better understand, empathize and negotiate with others in a global economy. Among the most useful skills are:

- Influence. Wielding effective persuasion tactics.

- Communication. Sending clear messages.

- Leadership. Inspiring and guiding groups and people.

- Change catalyst. Initiating or managing change.

- Conflict management. Understanding, negotiating and resolving disagreements.

- Building bonds. Nurturing instrumental relationships.

- Collaboration and cooperation. Working with others toward shared goals.

- Team capabilities. Creating group synergy in pursuing collective goals.

Goleman includes a set of emotional competencies within each construct of EI. Emotional competencies are not innate talents, but rather learned capabilities that must be worked on and can be developed to achieve outstanding performance. Goleman posits that individuals are born with a general emotional intelligence that determines their potential for learning emotional competencies. Goleman's model of EI has been criticized in the research literature as mere "pop psychology" (Mayer, Roberts, \& Barsade, 2008).

\section{d. The Measurement of Emotional Intelligence}

Two measurement tools are based on the Goleman model: 
1. The Emotional Competency Inventory (ECI), which was created in 1999, and the Emotional and Social Competency Inventory (ESCI), a newer edition of the ECI was developed in 2007. The Emotional and Social Competency - University Edition (ESCI-U) is also available. These tools developed by Goleman and Boyatzis provide a behavioral measure of the Emotional and Social competencies.

2. The Emotional Intelligence Appraisal, which was created in 2001 and which can be taken as a self-report or 360-degree assessment.

\section{RESEARCH METHOD}

This chapter presents the place and time of research, method of research, that describe how the research conducted, population and sample that mentions the target of research, technique of data collecting that explain about the techniques that the writer used to get the data, number of variable of research, kinds of instruments that are used in this research, technique how to analyze the data, and stating the statistic hypothesis.

A. Place and Time of Research

\section{Place of Research}

This research will be conducted on the third grader of Science class of state Senior High School students in Kramat Jati East Jakarta, there are at SMAN 14 Jakarta, SMAN 62 Jakarta, and SMAN 48 Jakarta in the academic year of 2014-2015.

2. Time of Research

The research process will be finished in by five months from arranging research proposal to the writing of thesis report.

A. Research design

The method of this research is survey method. Survey research is a research which is taking sample from some populations and by using questionnaire as the instruments of collecting data (Singarimbun, 2006: 3). He also said that a survey can be used explanatory or confirmatory. It means to explain the casual relation and testing a research hypothesis (Singarimbun, 2006: 111). Based on the explanation above the writer thinks that this research will be more precise to use correlation survey. It is 
because it will be revealed some facts on symptom of relations between free variables: Emotional Intelligence $(\mathrm{X})$ and towards bound variable Speaking skills (Y).

B. Population and Sample

1. Population

In this term of quantitative data, the writer used primary data that she got from the survey research. The source of data is from the respondents answer the questionnaires test (pronunciation test and speaking ability) and form document (emotional quotients score). The writer used statistical analysis (inferential/inductive) to calculate the numeral data that will be gathered and to analyze them by the use of correlation and regression analysis. The correlation coefficient is the interpretation to find out the effects of students' emotional intelligence towards students speaking skills.

From the explanation above, the writer take a conclusion that population is the object or subject in one area that and have certain conditions related to the research. The population will be used on this research are the students from Science classes on the third grade of state Senior High Schools in Kramat Jati East Jakarta which consist of three schools with the total number of students is 352 students. From the three schools above, the writer will take $25 \%$ from the total of the students of Science classes from those schools which is (number) of students. The students are chosen by using random sampling.

2. Sample

According to Arikunto (2006: 132) sample is a subject of a population which is studied. It is called sampling research if we intend to take the research conclusion as something that applies to the population. Similar terms are also presented by Jonathan Sarwono who defines sample as a unit from a set of elements which is chosen to be studied (Sarwono, 2006: 111). To get some proper samples it is needed the right technique (Sevilla, 1963: 163). According of Ida Bagus and Karto, even a sample is a part of population, some of the population is not always called a sample if the technique of collecting data is not improper.

C. Techniques of Data Collection 
The data collecting technique is a method which can be used by the researcher in collecting the data. They are the variables method and will be studied on this research. There are two kinds of data there are the data about students' Emotional Intelligence (X) which will be given to the students by filling the questionnaire. The last is students' speaking skills $(\mathrm{Y})$, as a bound variable. In the form of speaking score which will be given and done in an oral test at the school by the teacher him/herself.

D. Variables of Research

The most common are dependent and independent variable. An independent variable is presumed to be influenced by one or more than one variables. In this research which becomes a dependent variable is students' speaking skills $(\mathrm{Y})$, and which become independent variables is Emotional Intelligence (X).

E. Instrument of Research

1. The instrument of Emotional Intelligence

\section{a. Conceptual Definition}

Emotional Intelligence with the capacity to understand others' feelings, expose their talents, having a good relationship with other persons and etc. Emotional Intelligence as the part of human's intelligence completes the Intelligence Quotient in someone.

b. Operational Definition

To see Emotional Intelligence the writer use psychological questions test to the student which is divided into four dimensions; there are extrovert and introvert, sociability, impulsiveness, activeness, life excitability.

c. Types of Instrument

There was one documentation instrument, i.e. Emotional Intelligence instrument and two test instruments in this research; Emotional Intelligence and pronunciation test that were conducted by the writer. Each test was in the form of multiple choices, each test consisted of thirty questions with five alternative answers. The choice of multiple-choice type is based on the following considerations:

- It is easy and consistent

- It is easy to compute and determine the reliability of the test 
- It is economical because the number of items can be answered in a short period of the testing time

- It is more practical for the students to answer. They just marked the most appropriate answer in the answer sheet.

\section{The Instrument of Speaking Skills}

\section{a. Conceptual Definition}

Speaking skill is the ability to create sentences in the brain which has meaning and can be understood by the listeners. This skill is acquired slowly and progressively. One of the competencies on English lesson acquired at school is speaking, especially on the third grade of Senior High School.

b. Operational Definition

The data of students' ability in using english can be seen from the report score of speaking test at the school by the end of the semester.

c. The Specification of Speaking Skills

The instrument used to measure the speaking skill is in the form of objectives test. Students are required to answer some questions orally.

F. Validity Test

The advisability of the instrument variable on students' speaking skills and Emotional Intelligence can be explained through validity test which is score that prove the measurement ability of the instrument.

Moreover, in order to having criterion-related evidence of validity (the result proper with the criteria), the writer used Pearson Product Moment Correlation Techniques to find out the correlation between the result of test and the criteria. The formula is as follow:

$\mathrm{r}_{\mathrm{xy}}=\frac{\mathrm{n} \sum \mathrm{X}_{\mathrm{i}} \mathrm{Y}_{\mathrm{i}}-\left(\sum \mathrm{X}_{\mathrm{i}}\right)\left(\sum \mathrm{Y}_{\mathrm{i}}\right)}{\sqrt{\left\{\mathrm{n} \sum \mathrm{i}^{2}-\left(\sum \mathrm{X}_{\mathrm{i}}\right)^{2}\right\}\left\{\mathrm{n} \sum \mathrm{Y}_{\mathrm{i}}^{2}-\left(\sum \mathrm{Y}_{\mathrm{i}}\right)^{2}\right\}}}$

In which:

$r_{\mathrm{xy}}=$ correlation coefficient

$\mathrm{n}=$ number of try out respondents

$\mathrm{X}=$ the score number of each item

$\mathrm{Y}=$ the sum score number of each items 
The interpretation of correlation coefficient is as follow:

$\mathrm{r}_{\mathrm{xy}}=0,800-1,00$ : very strong correlation

0,600-0,800 : strong correlation

$0,400-0,600$ : satisfactory correlation

$0,200-0,400$ : low correlation

0,00-0,200 : very low correlation

After obtaining the $r_{\mathrm{xy}}$ value for each item, then it should be consulted to the critical value of $r_{\text {table }}$ to find out the significance correlation. In this case, for $\alpha=0.05$ with the number of subjects is thirty, the value of $r_{\text {table }}$ is 0.374 and an item is said to be valid if $r_{x y}$ $>\mathrm{r}_{\text {table }}$, and vice versa. In this case, the calculation is aided by ANATES ver.4 software developed by Drs. Karnoto M. Pd and Yudi Wibisono ST.

G. Reliability

Reliability means the stability of the test scores. A test cannot measure anything well unless it measures consistently. To know whether the items are reliable or not, the writer will apply Kuder Richardson-21 formula since the item is in the form of multiple choices.

Then, the calculation is aided by ANATES ver.4 software.

The interpretation:

$\mathrm{R}_{11}=0,8-1,0$ the reliability is excellent

$0,6-0,8$ the reliability is good

$0,4-0,6$ the reliability is satisfactory

$0,2-0,4$ the reliability is poor

$0,0-0,2$ the reliability is very poor

H. Test Item Analysis

a. Level of Difficulty

Arikunto (2009:207) said that a good test item should not be either too easy or too difficult. An easy test will not stimulate students to figure it out. An excessively difficult one, on the other hand, makes students desperate and be reluctant to try to solve it.

I. Technique of Data Analysis

1. Descriptive Analysis Technique

Descriptive analysis technique is testing the data of research result by presenting data in basic statistic including frequency distribution, histogram, mean, median, mode, and variance.

2. Statistic Technique (SPSS) 
Data from the research result will be analyzed through statistic test by using SPSS 17.0 software. Ridwan (2009:39) stated that before conducting the hypothesis test, the requirements or assumptions of data analysis must be fulfilled first, such as the data were selected randomly, the data must be fulfilled the basic assumption test like normality, linearity, and homogeneity test, and the data must be in the interval scale. If all the requirements have been fulfilled, then the hypothesis test will be conducted.

a. The data were selected randomly

This requirement has been fulfilled since the research samples are selected randomly with the amount of as sample is 110 .

b. The data must be fulfilled the basic assumption tests

Basic assumption test will be conducted to find out whether the data can be used in analysis and further calculation. The test includes normality, homogeneity, and linearity test.

1) Normality Test

Normality in the regression model is used to test whether the residual value resulting from the regression are normally distributed or not. A good regression model that has a residual value is normally distributed. Some methods of test for normality are:

a. By looking at the data distribution of diagonal line on the graph Normal PP plot of regression standardized residual Or

b. By one sample Kolmogorov-Smirnov test.

Here, the test data normality will be done by those methods. One sample of Kolmogorov-Smirnov test is used to determine the distribution of data, whether follow normal distribution, poison, uniform, or exponential. In this case is whether the distributions of residuals are normally distributed or not. The test that show the normal data is significance if the significance value or $\mathrm{p}$ value (asymp.sig) $>0$, 05. (Santoso, 2009)

2) Linearity test

The result of linearity test that is used to test whether the data that will be analyzed i.e. independent variable towards dependent variable is in linear on not. The testing criteria is if the number of the deviation from the linearity is more than $0,05(>0$, 
05), it means that the correlation between independent variable and dependent variable is linear based on the result of probability sig. calculation.

3) Homogeneity Test

Homogeneity means that the data as a sample in the sample has the same characteristics; for example, comes from the same grade. Here, the data is homogeny since the data comes from the same grade (third grade of senior high school).

The homogeneity test is done as a prerequisite in the analysis of independent sample t-test and ANOVA. The underlying assumption in the analysis of variance (ANOVA) is that the variance of the population is homogenous. The calculation of homogeneity test can be done in various ways and methods; some quite popular and frequently used by the author such as Barlett test, Variance Test (F test) and Levine test.

Here, the writer used Levene Statistic Test to the test of homogeneity of data. To calculate the Levine Test with SPSS is select the menu: analyze $>$ compare means $>$ one-way ANOVA, and to interpret the Levene Test is, if significance value of Test of Homogeneity of Variance is more than 0,05 . It can be said that the variation of data is homogenous.

c. The data must be in interval scale

The data that will be analyzed must be in interval scale by changing the raw data to the standard data or raising the original data to be the interval data, by using the following formula (processing aided by Microsoft Excel 2007).

$$
\mathrm{T}_{\mathrm{i}}=50+10 \frac{\left(\mathrm{X}_{\mathrm{i}}-\mathrm{x}\right)}{\mathrm{s}}
$$

In which:

$\mathrm{T}_{\mathrm{i}} \quad$ : standard score (interval data)

$\mathrm{X}_{\mathrm{i}} \quad$ : standard score (original data)

$\mathrm{X}$ : mean

S : standard deviation.

Ridwan (2009:295)

d. Hypothesis Test 
After the data collected, the writer analyzed data to examine the hypothesis. In this case, the writer used statistic calculation: multiple regression linearity analysis. It consists:

1) Regression Analysis

\section{a. Multiple Correlation Analysis (R)}

The analysis of multiple correlation coefficient value $R$ that can be seen as the model summary output that will be processed by using SPSS 17 program.

b. Determination analysis $\left(\mathrm{R}^{2}\right)$

To explain the contribution value of independent variable $(\mathrm{X})$ towards dependent variable $(\mathrm{Y})$, it can be determined by $\mathrm{R}^{2}$ value. The determinant coefficient formula is as follow:

$\mathrm{KP}=\mathrm{R}^{2} \mathrm{X} 100 \%$

$\mathrm{KP}$ :determinant coefficient value

$\mathrm{R} \quad$ :correlation coefficient value

c. Regression Coefficient Test Concurrently (F-Test)

This test is using $\mathrm{F}$ test with significance level $=5 \%$ to test the hypothesis 1 whether or not there is an influence of intelligence quotient and vocabulary mastery concurrently towards reading comprehension at the third grade of science senior high school students in Kramat Jati East Jakarta in 2013/2014.

d. Regression Coefficient Test Partially (T-Test)

e. Statistic Hypothesis

Based on the hypothesis that has been formulated, thus the statistics hypothesis in this research are as follow:

\section{Hypothesis 1}

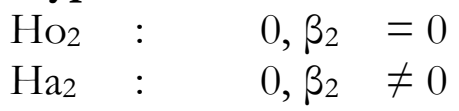

$\mathrm{Ho}_{2}=$ There is no influence of students' Emotional Intelligence towards speaking skills at the third grade of science Senior High School students in Kramat Jati East Jakarta in 2014/2015.

$\mathrm{Ha}_{2}=$ There is a significant influence of students' Emotional Intelligence quotient towards speaking skills at the third grade of Science Senior High School students in Kramat Jati East Jakarta in 2014/2015.

Note: 
Ho = null hypothesis

$\mathrm{Ha} \quad=$ research hypothesis

$\beta_{1}=$ Correlation coefficient of students' Emotional Intelligence, Pronunciation Mastery towards speaking skills at the third grade of science Henior High School students in Kramat Jati East Jakarta in 2014/2015.

$\beta_{2}=$ Correlation coefficient of students' Emotional Intelligence and speaking skills at the third grade of science Senior High School students in Kramat Jati East Jakarta in 2014/2015.

$\beta_{3}=$ Correlation coefficient of students' Pronunciation Mastery and Speaking Skills at the third grade of science Senior High School students in Kramat Jati East Jakarta in 2014/2015.

\section{FINDINGS AND DISCUSSION}

The things address data description requirement test, testing of hypotheses, and also interpretation of research. More detailed discussion related to research findings is clearly depicted below:

\section{A. The Description of Data}

The researcher analyzes the data from both the questionnaire and also the test. Data are taken from emotional intelligence questionnaire, pronunciation mastery objective test and speaking skill oral test out of 60 respondents where all the data are previously sentenced to be valid and reliable. The aim of the analysis is to find out and give the information of the research findings based on the data and variables of the research subject. Therefore, all data will be analyzed by using Statistical Program for Social Science (SPSS) version 20.0 for Windows in order to get the results of the relationships among variables.

\section{The Data of Emotional Intelligence $\left(\mathbf{X}_{1}\right)$}

Data of emotional intelligence are taken from a questionnaire given to the students to complete. The questionnaire consists of 30 items as emotional quotient out of 60 respondents. Each item will be graded from 1 (strongly disagree) to 5 (strongly agree) with Likert scale.

It is known that the score are in the range $94-112$. It means that the minimum score is 94 and the maximum score is 112. We can see that the emotional quotient level of the 
respondents is on the average 103.5 (mean), standard deviation 4.69, median (score at center of distribution) 104 and mode (most frequently score in the data set) 103 . The score of standard deviation is 4.69 , which means equal to $4.5 \%$ from the average score. It shows that the disparity of emotional intelligence among the respondents is relatively low. So we can conclude that emotional intelligence level of the respondents is homogenous.

From the description of Table 4.1 above, we either can see that the average score and median score is almost the same, by 103.5 and 104. It means that data of emotional intelligence level is quite representative. Meanwhile, the upper emotional intelligence level which is higher than that of the average, it indicates that the respondents who possess the upper-level of emotional intelligence are more than those of the lower-level ones.

Furthermore, the graph of frequency histogram illustrates the distribution of emotional intelligence scores as follows:

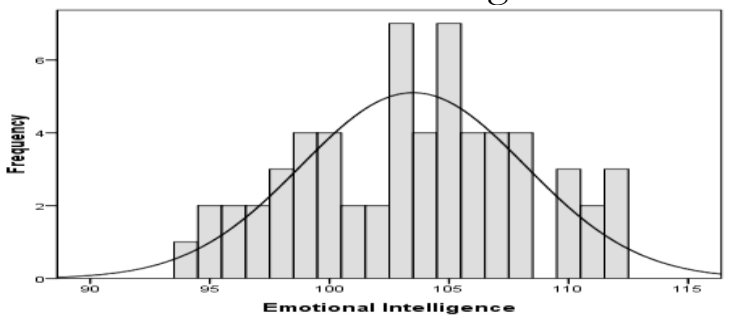

\section{The Data of Speaking Skill (Y)}

Data of student's speaking skill are taken through an oral test. The test consists of 5 items criteria out of 60 respondents. Each item will be graded from 1 to 5 , refer to the skill she/he has while speaking, namely: 5 for outstanding, 4 for excellent, 3 for good, 2 for fair and 1 for need improvement.

It is known that the score are in the range $15-23$. It means that the minimum score is 15 and the maximum score is 23 . The speaking skill level of the respondents is on the average 18.82 (mean), standard deviation 2.09, median (score at center of distribution) 19 and mode (most frequently score in the data set) 19. The score of standard deviation is 2.09 , which means equal to $11.1 \%$ from the average score. It shows that the disparity of 
speaking skill among the respondents is relatively low. So we can conclude that speaking skill level of the respondents is relatively homogenous.

From the description of table 4.1 above, we either can see that the average score and median score is almost the same, by 18.82 and 19. It means that data of speaking skill level is quite representative. Meanwhile, the upper speaking skill level which is higher than that of the average, it indicates that the respondents who possess the upper-level of speaking skill are more than those of the lower-level ones.

Furthermore, the graph of frequency histogram illustrates the distribution of speaking skill scores as follows:

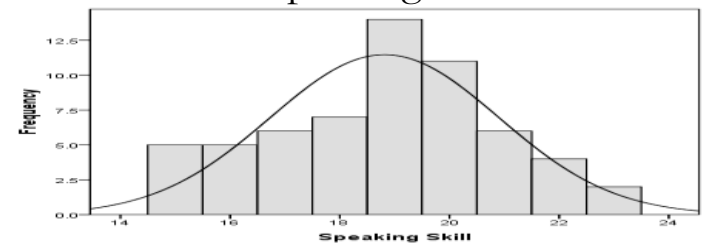

B. Prerequisite Tests for the Data Analysis

1. Normality Test

Normality test is used to test and determine whether the data normal or not so that tobserved, partial correlation, multiplecorrelation, single-regression and multiple-regression can be analyzed. In this survey research, there are 60 students to be the respondents. However, Sudjana (1989:64) and Hadi (1986:70) point out that a total number of respondents are same or more than 30 . It means that the total respondents of this survey research answer the requirement.

2. Linearity Test

Linearity test is an assumption in the regression analysis. It means that the regression line between $\mathrm{X}$ and $\mathrm{Y}$ forming whether or not in the linear line. If the line is not linear, it cannot be automatically continued to the next step of computation. 


\begin{tabular}{|c|c|c|c|c|c|c|c|}
\hline \multicolumn{8}{|c|}{ ANOVA Table } \\
\hline & & & $\begin{array}{l}\text { Sum of } \\
\text { Squares }\end{array}$ & $d f$ & Mean Square & $\mathrm{F}$ & Sig. \\
\hline \multirow{5}{*}{$\begin{array}{l}\text { Speaking Skill } \\
\text { Emotional Intelligence }\end{array}$} & \multirow[t]{3}{*}{ Between Groups } & (Combined) & 136.912 & 17 & 8.054 & 2.817 & .003 \\
\hline & & Linearity & 84.598 & 1 & 84.598 & 29.592 & .000 \\
\hline & & Deviation from Linearity & 52.314 & 16 & 3.270 & 1.144 & .350 \\
\hline & Within Groups & & 120.071 & 42 & 2.859 & & \\
\hline & Total & & 256.983 & 59 & & & \\
\hline
\end{tabular}

The test of linearity in this survey research will follow the hypothesis as follows:

$\mathrm{H}_{0} \quad$ : the regression line between variable $\mathrm{X}$ and variable $\mathrm{Y}$ is linear.

$\mathrm{H}_{1} \quad$ : the regression line between variable $\mathrm{X}$ and variable $\mathrm{Y}$ is not linear.

The linearity test of the regression line can be calculated by using SPSS version 20 .0 for Windows. According to the normal assumption, the set of data will be classified as linear in regression line if Sig. value is higher than 0.05 which means the $\mathrm{H}_{0}$ is accepted and automatically $\mathrm{H}_{1}$ is rejected. (Nurgiantoro et al., 2009:329). The Sig. value is a number which is located in Sig. column of Deviation from Linearity in ANOVA table as the result of calculation of linearity test through SPSS version 20.0 for Windows.

a. Linearity of Regression Line the Effect of Emotional Intelligence $\left(\mathrm{X}_{1}\right)$ towards Student's Speaking Skill $(\mathrm{Y})$

b. Linearity Test Result of Regression Line the Effect of Emotional Intelligence $(\mathrm{X})$ and Student's Speaking Skill (Y)

Based on the Table 4.3 above, the Sig value from Deviation from Linearity column is 0.350 . It means that the value is higher than 0.05 . As the consequence, $\mathrm{H}_{0}$ is accepted and automatically $\mathrm{H}_{1}$ is rejected. In other words, we can say that the regression line which indicates the effect of emotional intelligence $\left(\mathrm{X}_{1}\right)$ towards student's speaking skill (Y) is linear.

\section{Testing of Hypotheses}

Testing of hypotheses is done based on statistical hypotheses in last part of chapter III. The recapitulation can be seen in the set of following tables:

The Recapitulation Result of Multiple Correlation Coefficients of the Effects of Emotional Intelligence (X) towards Student's Speaking Skill 
Model Summary

\begin{tabular}{|l|l|r|r|r|}
\hline $\begin{array}{l}\text { Mode } \\
\perp\end{array}$ & $\mathrm{R}$ & $\mathrm{R}$ Square & $\begin{array}{c}\text { Adjusted R } \\
\text { Square }\end{array}$ & $\begin{array}{c}\text { Std. Error of } \\
\text { the Estimate }\end{array}$ \\
\hline 1 & $.70 \mathrm{~g}^{\mathrm{a}}$ & .503 & .486 & 1.496 \\
\hline
\end{tabular}

a. Predictors: (Constant), Pronunciation Mastery, Emotional Intelligence

Based on the three tables above, the testing of hypotheses is formulated both statistically and verbally in the following:

\section{The Effect of Emotional Intelligence (X) towards Student's Speaking Skill (Y)}

$\mathrm{H}_{0} \quad: \beta_{2}=0$

$\mathrm{H}_{1} \quad: \beta_{2} \neq 0$

\section{Explanation:}

$\mathrm{H}_{0}$ : There is no effect of emotional intelligence towards student's speaking skill.

$\mathrm{H}_{1}$ : There is an effect of emotional intelligence towards student's speaking skill. To test the hypothesis above, we can simply see from the numbers which are stated in t column or Sig column in the row of emotional quotient on Table 4.7. According to general assumption, the significance of regression is if tobserved is higher than table or Sig value is less than 0.05 , it brings consequence that $\mathrm{H}_{0}$ is rejected and $\mathrm{H}_{1}$ is automatically accepted. It means that there is an effect of the independent variable $\mathrm{X}_{1}$ towards the dependent variable Y. Sig value is the number which is stated in Sig column for the row of emotional intelligence (Variable $\mathrm{X}_{1}$ ) on the Table 4.7. Meanwhile tobserved value is the number which is stated in t column for emotional intelligence (Variable $\mathrm{X}_{1}$ ) on table 4.7 as well. For the value of $t_{\text {table }}$ for $5 \%$ real degree and degree of freedom $(\mathrm{df}=\mathrm{n}-2)$ is 58 , where $\mathrm{n}$ is the total number of respondents.

Refer to Table 4.7 above, we can see that Sig value is stated by 0.000 and $t_{\text {observed }}$ is stated by 4.375 , while $t_{\text {table }}$ is stated by 2.00 . Since Sig value is less than 0.05 and tobserved is higher than table, it brings consequence that $\mathrm{H}_{0}$ is rejected and automatically $\mathrm{H}_{1}$ is accepted. It means that there is a significant effect of independent variable $\mathrm{X}$ (emotional intelligence) towards the dependent variable Y (student's speaking skill). 
From the tabulation of correlation test, regression test and linear model above, we can conclude that there is a significant effect of independent variable $\mathrm{X}$ (emotional intelligence) towards the dependent variable Y (student's speaking skill).

\section{CONCLUSION AND IMPLICATIONS}

Based on the results of hypothesis testing and discussion of research findings, on this chapter presented conclusions and suggestions that are synthetic and systemic. The general conclusions which form the basis for further assessment will be presented in the form of research suggestions.

Some conclusions of this research can be presented as follows:

1. There are any significant effects of emotional intelligence towards student's speaking skill of XII grade student at State Senior High School in East Jakarta. It is proved by the score of $F_{\text {observed }}=28.879$ and Sig. 0.000 $<0.05$. This indicates that the emotional intelligence and pronunciation mastery are two critical variables to be considered in explaining the increase of student's speaking skill.

2. There is a significant effect of emotional intelligence towards student's speaking skill of XII grade student at State Senior High School in East Jakarta. It is proved by the score of tobserved $=4.375$ and Sig. $0.000<0.05$. This means that the better the emotional intelligence, the better the student's speaking skill, or vice versa. Therefore, emotional intelligence is an important variable to consider in predicting the student's speaking skill.

Refer to the research findings as illustrated before; it is proven that the student's speaking skill is mostly affected by emotional intelligence and pronunciation mastery. Therefore, efforts to improve the student's speaking skill must be accompanied by efforts to optimize the emotional intelligence and pronunciation mastery. 
Efforts to improve the student's speaking skill through the optimization of emotional intelligence: a) to open up the student's mind in the beginning of learning, learning processes and outcomes; b) to inform the students about the importance of emotional intelligence as endorsing factors in learning; c) to direct the learning process professionally; d) to optimize the emotional intelligence by managing the emotion through social relationship; e) to maintain the control of emotion so that student will be able to communicate effectively and dynamically in context of learning. With these efforts are expected that emotional intelligence will work optimally and as the result will bring betterment for student's skill in English speaking.

\section{REFERENCES}

Barlow, D. H. (Ed.). (1985). Clinical handbook of psychological disorders: A stepby-step treatment manual. New York: Guilford Press.

Bar-On, R. (2000). Emotional and social intelligence: Insights from the Emotional Quotient Inventory (EQ-i). In R. Bar-On \& J.D.A. Parker (Eds.), Handbook of emotional intelligence (pp. 363388). San Francisco: Jossey-Bass.

Brown, D. H. (2004). Language assessment: Principles and classroom practices. New York: Pearson-Education. Inc.

Cavallo, K. \& Brienza., D. (2002). Emotional competence and leadership excellence at Johnson \& Jobnson. New Brunswick, NJ: Consortium for Research on Emotional Intelligence in Organizations, Rutgers University.

Goleman, D. (2001). Emotional intelligence: Issues in paradigm building. In C. Cherniss \& D. Goleman (Eds.), The emotionally intelligent workplace, (pp. 13-26), Jossey-Bass: San Francisco.

Goleman, D. (1998). Working with emotional intelligence. New York: Bantam Books.

Goleman, D., Boyatzis, R., \& McKee, A. (2002). Primal leadership: Realizing the power of emotional intelligence. Boston: Harvard Business School Press.

Goleman, D., Boyatzis, R. E., \& Rhee, K. S. (2000). Clustering competence in emotional intelligence: Insights from the emotional competence inventory. In R. Bar-On and J.D.A. 
Sulistyawati, M. E. S., The Effects of...

Parker (Eds.), Handbook of emotional intelligence (pp. 343-362). San Francisco: Jossey-Bass.

Mayer, J. D., \& Salovey, P. (1997). What is emotional intelligence? In P. Salovey and D. Sluyter (Eds.), Emotional development and emotional intelligence: Implications for Educators (pp. 3-34). New York, NY: Basic Books.

Mayer, J. D., Salovey, P., \& Caruso, D. R. (2000). Emotional intelligence as zeitgeist, as personality, and as a mental ability. In R. Bar-On and J.D.A. Parker (Eds.), Handbook of emotional intelligence (pp. 92-117). San Francisco: Jossey-Bass.

McClelland, D. C. (1973). Testing for competence rather than intelligence. American Psychologist, 28, 1-14.

McCrae, R. R. (2000). Emotional intelligence from the perspective of the five-factor model of personality. In R. Bar-On \& J.D.A. Parker (Eds.), Handbook of emotional intelligence (pp. 263276). San Francisco: Jossey-Bass.

Sternberg, R. J. (1997). Successful intelligence. New York: Plume.

Sternberg, R., Lautrey, J., \& Lubert, T. I. (2002). Where are we in the field of intelligence, how did we get here, and where are we going. In Models of Intelligence: International Perspectives, R. J. Sternberg, J. Lautrey, T. I. Lubart (Eds.) (pp. 3-25). Washington D.C. American Psychological Association. 